IZA DP No. 8948

Man-cessions, Fiscal Policy, and the Gender Composition of Employment

Christian Bredemeier

Falko Juessen

Roland Winkler

March 2015 


\title{
Man-cessions, Fiscal Policy, and the Gender Composition of Employment
}

\author{
Christian Bredemeier \\ University of Cologne \\ Falko Juessen \\ University of Wuppertal \\ and IZA \\ Roland Winkler \\ TU Dortmund University
}

\section{Discussion Paper No. 8948 \\ March 2015}

\author{
IZA \\ P.O. Box 7240 \\ 53072 Bonn \\ Germany \\ Phone: +49-228-3894-0 \\ Fax: +49-228-3894-180 \\ E-mail: iza@iza.org
}

\begin{abstract}
Any opinions expressed here are those of the author(s) and not those of IZA. Research published in this series may include views on policy, but the institute itself takes no institutional policy positions. The IZA research network is committed to the IZA Guiding Principles of Research Integrity.

The Institute for the Study of Labor (IZA) in Bonn is a local and virtual international research center and a place of communication between science, politics and business. IZA is an independent nonprofit organization supported by Deutsche Post Foundation. The center is associated with the University of Bonn and offers a stimulating research environment through its international network, workshops and conferences, data service, project support, research visits and doctoral program. IZA engages in (i) original and internationally competitive research in all fields of labor economics, (ii) development of policy concepts, and (iii) dissemination of research results and concepts to the interested public.
\end{abstract}

IZA Discussion Papers often represent preliminary work and are circulated to encourage discussion. Citation of such a paper should account for its provisional character. A revised version may be available directly from the author. 
IZA Discussion Paper No. 8948

March 2015

\section{ABSTRACT \\ Man-cessions, Fiscal Policy, and the Gender Composition of Employment}

In recessions, predominantly men lose their jobs, which has given rise to the term "mancessions". We analyze whether fiscal expansions bring men back into jobs. To do so, we estimate vector-autoregressive models and identify the effects of fiscal shocks and non-fiscal shocks on the gender composition of employment. We show that contractionary non-fiscal shocks lead to man-cessions, i.e. employment falls and more strongly so for men. By contrast, an expansionary fiscal shock predominantly raises the employment of women. Taken together, these results imply a trade-off dilemma for policy that seeks to stabilize the level of employment along with its composition.

JEL Classification: E24, E32, J10, J21

Keywords: employment, gender, fiscal policy, business cycles

Corresponding author:

Falko Juessen

University of Wuppertal

Gaußstraße 20

42119 Wuppertal

Germany

E-mail: juessen@uni-wuppertal.de 


\section{Introduction}

In economic downturns, predominantly men are laid off. This observation received particular attention in the public debate during the Great Recession when the term "man-cession" was coined. ${ }^{1}$ For example, between 2007Q3 and 2009Q1, more than three out of four (78\%) of the jobs lost in the US were held by men. In relative terms, male employment fell by $4.8 \%$ while female employment fell by only $1.4 \%$. Notably, the observation of man-cessions is neither restricted to the Great Recession nor to the US economy. For instance, Wall (2009) and Hoynes, Miller, and Schaller (2012) have documented similar observations during every recession since 1968. Similarly, Contessi and $\mathrm{Li}$ (2014) have found evidence for stronger surges in male unemployment in each of the G7 countries and the OECD as a whole during the 2007-2009 downturn.

Against this background, fiscal policy deserves particular attention. Expansionary fiscal policy not only intends to stabilize the total level of employment, but stabilizing the distribution of employment is often an additional, major goal of fiscal policy in times of crisis. For example, point 2 in the statement of purpose of the ARRA stimulus of 2008 stated that it was the bill's goal "to assist those most impacted by the recession". According to the evidence above, those most impacted by the recession were predominantly men. In fact, some commentators criticized the ARRA stimulus for the supposed gender composition of the created jobs. ${ }^{2}$

In this paper, we investigate the effects of fiscal policy on the distribution of employment by gender. We estimate vector-autoregressive (VAR) models and identify fiscal and non-fiscal (business-cycle) shocks using sign restrictions. We consider sign restrictions as the most suitable identification procedure for our purposes because this method allows us to easily discriminate between fiscal policy on the one hand and all other drivers of the business cycle on the other hand. Specifically, our econometric treatment informs us whether non-fiscal shocks are associated with man-cessions in the first place, at the same time being informative about whether fiscal shocks have a different effect than non-fiscal shocks on the gender composition of employment. The VAR models are estimated on quarterly time series data for the US covering the period 1964Q1 to 2013Q4. Our baseline VAR includes data on GDP, the primary budget deficit, employment, and

\footnotetext{
${ }^{1}$ Economist Mark Perry, who coined the term, testified on the issue of man-cessions before the Means and Ways committee of the US congress on June 17, 2010.

${ }^{2}$ Interestingly, both directions of gender inequity have been discussed, see, for instance, the contributions by Christina Hoff Sommers in the Weekly Standard (Jun. 29, 2009) and by Bryce Covert in the Huffington Post (Sep. 24, 2010).
} 
the employment ratio between women and men. Fiscal shocks and non-fiscal shocks are identified via sign restrictions on the responses of GDP and the primary deficit, following Pappa (2009).

Our results confirm that man-cessions are an important and robust feature of the business cycle. We show that non-fiscal shocks generate a negative co-movement between the relative employment of women and aggregate measures of the business cycle such as GDP or employment. This means that male employment is more responsive to cyclical changes than female employment, which is in line with previous evidence on man-cessions, reviewed below.

Most interestingly, we document that the reverse holds for fiscal policy shocks. Fiscal shocks lead to a positive co-movement between aggregate measures of the business cycle and the relative employment of women. This means that, in response to fiscal expansions, the employment of women rises significantly more strongly than the employment of men.

Taken together, this has striking policy implications. Men are hit hardest in recessions but a fiscal stimulus predominantly fosters job creation for women. Thus, fiscal policy faces a trade-off dilemma. On the one hand, the goal of fiscal policy is to stabilize the total level of employment. On the other hand, fiscal policy intends to stabilize the composition of employment. Our results suggest that fiscal policy can only achieve one of these goals. If a contractionary non-fiscal shock is counteracted by a fiscal stimulus, the drop in aggregate employment is cushioned but more women than men are brought into jobs. In turn, this amplifies the fluctuation in the gender composition of employment.

In a second part of the paper, we perform a sequence of additional evaluations in order to explore the role of sectors, occupations, and industries for our results. Specifically, we first investigate the dynamics of government employment to account for a potential composition effect, as women are over-represented in the government sector. In fact, the increase in government employment after an expansionary fiscal shock partly explains why fiscal policy has a stronger effect on female than on male employment but this composition effect is quantitatively small. From a quantitative point of view, a more important effect is that expansionary fiscal shocks cause employment in femaledominated, so-called "pink-collar", occupations to rise disproportionately. This leads to an increase in the aggregate share of female employment and appears to be important for understanding the female-biased employment effects of fiscal policy. By contrast, composition effects reflecting the 
industry mix of created jobs are found to be less important. However, we show that industry effects are important for understanding why non-fiscal shocks are associated with man-cessions in the first place. This lends support to the view on man-cessions discussed in the existing literature (e.g., Hoynes, Miller, and Schaller 2012).

Our paper is related to the literature investigating gender differences in employment cyclicalities, see, e.g., Clark and Summers (1981), Ewing, Levernier, and Malik (2002), Ewing, Levernier, and Malik (2005), Elsby, Hobijn, and Şahin (2010), or Hoynes, Miller, and Schaller (2012). ${ }^{3}$ This literature has shown that men bear a disproportionately high share of cyclical employment variation. Our results with respect to the effects of non-fiscal shocks corroborate this finding. Our main contribution to this literature is to provide evidence on the effects of fiscal expansions on the gender composition of employment. Giavazzi and McMahon (2012) have investigated the effects of a specific fiscal shock, increases in military spending, on different population groups. Their finding that military spending increases hours worked disproportionately in households with female heads is broadly consistent with our results.

The remainder of this paper is organized as follows. Section 2 presents our baseline VAR model and the main results. Section 3 explores potential explanations of our results. Section 4 concludes.

\section{The effects of fiscal shocks on the gender composition of employment}

In this section, we present our baseline model, the identifying restrictions, and the results of the estimated model. We estimate a vector-autoregressive model and use sign restrictions to identify the effects of fiscal policy shocks and non-fiscal shocks on the gender composition of employment. Our baseline VAR includes constants and three lags of quarterly US data on the primary fiscal deficit, real GDP, aggregate employment, and the employment ratio between women and men. ${ }^{4}$ Our main interest is on the reaction of the gender employment ratio to different shocks. A significant reaction of the gender employment ratio is tantamount to a significantly different response of male and female employment to the respective shock. All variables are measured as percentage deviations from HP trends. Our baseline sample starts in 1964Q1 and ends in 2013Q4. The reduced

\footnotetext{
$3_{3}$ Jefferson (2005), Jefferson (2008), Rodgers (2008) have studied employment fluctuations for other population groups than gender.

${ }^{4}$ See Appendix A for details on data sources and data construction.
} 
form VAR reads

$$
y_{t}=c+\sum_{i=1}^{3} A_{i} y_{t-i}+\varepsilon_{t},
$$

where the vector $y_{t}$ includes the variables described above and $c$ is a vector of constants, $A=$ $\left[A_{1}, A_{2}, A_{3}\right]$ is the coefficient matrix, and $\varepsilon_{t}$ is the vector of reduced-form residuals. We estimate the reduced-form VAR with Bayesian techniques using a Minnesota prior. ${ }^{5}$

We identify a fiscal and a non-fiscal shock using sign restrictions. We impose, following Pappa (2009), that an expansionary fiscal policy shock (which can be a spending increase or a tax cut or a combination of both) raises the primary deficit and output. ${ }^{6}$ By contrast, non-fiscal (businesscycle) shocks affect the deficit and output in opposite directions. These identifying restrictions can be derived from mild assumptions: expansionary fiscal policy raises output and the endogenous component of fiscal policy is not too procyclical (i.e., in non-fiscally induced booms, government spending does not rise endogenously by more than tax revenues). In order to study fiscal stimuli that bring people into jobs, we impose a further sign restriction on the employment response to fiscal shocks. We impose the sign restrictions on impact and in the following three quarters.

Formally, our identification proceeds as outlined in Uhlig (2005). We take a draw $\widetilde{A}$ from the posterior distribution of the coefficient matrix $A$ and calculate the Cholesky decomposition of the estimated covariance matrix $\widehat{\Sigma}=B B^{\prime}$. We then take a draw $\omega$ from the four-dimensional unit sphere by applying a QR decomposition of a $4 \times 4$ matrix of random numbers drawn from the standard normal distribution. We consider shocks $b=B \omega$ and the impulse response functions to $b$. If they satisfy the sign restrictions, we keep the draw $(\widetilde{A}, \omega)$ and save the impulse response functions. This procedure is repeated until 10,000 responses to both fiscal and non-fiscal shocks are found. For each shock, we order the responses of the 10,000 accepted models to obtain a posterior distribution at each horizon.

Figure 1 summarizes the estimated responses of the variables in our baseline VAR. We display the median together with the 16th-84th percentiles of the distribution of responses in the accepted

\footnotetext{
${ }^{5}$ Specifically, for the variance-covariance matrix of the reduced-form shocks $\Sigma$, we us the estimate $\widehat{\Sigma}$ from an OLS estimation of the VAR. The prior means for all entries in $c$ and $A$ are zero. For constants, we set the prior variance of the coefficients to 100 and to $0.5 \cdot \frac{\sigma_{j j}}{L^{2} \cdot \sigma i i}$ for the impact of the $L$ 'th lag of variable $j$ on variable $i$, where $\sigma_{i i}$ and $\sigma_{j j}$ are diagonal entries from the estimate of the variance-covariance matrix of the reduced-form shocks.

${ }^{6}$ A similar identification of fiscal shocks has been used by Enders, Müller, and Scholl (2011).
} 
models. These probability bands reflect Bayesian parameter uncertainty and identification uncertainty. The horizontal axes show quarters after the shock and the responses are expressed in percentage terms. Quantitatively, the responses are rescaled to the case where, at the median, GDP changes by one percent on impact. The reactions of the deficit, output, and - in case of the fiscal shock - aggregate employment follow the sign restrictions. After a favorable non-fiscal shock, we also observe a rise in aggregate employment.

Our main interest is on the reaction of the gender employment ratio, displayed in the lower right panels of Figures 1(a) and 1(b), respectively. After a favorable non-fiscal shock, the female to male employment ratio falls significantly. Three quarters after the shock, the response of the gender ratio is negative in $94.1 \%$ of the accepted models. As aggregate employment rises, this means that male employment rises more strongly than female employment. In the case of an adverse non-fiscal shock, this means that aggregate employment falls and predominantly male jobs are lost. Thus, our estimated model shows that contractionary non-fiscal shocks induce man-cessions.

Strikingly, and contrary to the non-fiscal shock, we observe a pro-cyclical response of the female to male employment ratio conditional on fiscal shocks, see the bottom-right panel in Figure 1(b). After a favorable fiscal shock, there is a significant and delayed rise in the female to male employment ratio. One year after the shock, $88.1 \%$ of the accepted models show a positive response of the gender employment ratio and this number increases to $97.0 \%$ in quarter 10 after the shock. As aggregate employment rises, see the bottom-left panel of Figure 1(b), one can conclude that female employment rises more strongly than male employment in response to expansionary fiscal shocks. Thus, a fiscal stimulus brings predominantly women into jobs.

We now provide some back-of-the-envelope calculations for the absolute employment change implied by the median responses. ${ }^{7}$ One year after a contractionary non-fiscal shock which leads to a decline in GDP by one percent, about 770,000 jobs have been lost, about 495,000 of which were held by men, corresponding to roughly two thirds of the jobs lost. As a comparison, in the Great Recession, this number was about three quarters. By contrast, one year after a positive

\footnotetext{
${ }^{7}$ The percentage changes in male and female employment can be determined from the responses of aggregate employment and the gender employment ratio. Let $\widehat{n}_{F}, \widehat{n}_{M}, \widehat{n}=s_{F} \widehat{n}_{F}+s_{M} \widehat{n}_{M}$, and $\widehat{r}=\widehat{n}_{F}-\widehat{n}_{M}$ denote the percentage trend deviations of female employment, male employment, total employment, and of the employment ratio, respectively. $s_{F}$ and $s_{M}$ are the mean shares of women and men in total employment, respectively. From our estimations, we take the medians of $\widehat{n}$ and $\widehat{r}$ and calculate $\widehat{n}_{M}=\widehat{n}-s_{F} \widehat{r}$ and $\widehat{n}_{F}=\widehat{n}_{M}+\widehat{r}$. The long-run means of total employment, female employment, and male employment in our sample are about 111 million, 46 million, and 65 million, respectively. Multiplying with relative changes gives the total job changes provided in the text.
} 
Figure 1: Impulse responses in baseline VAR.

(a) Non-fiscal shock
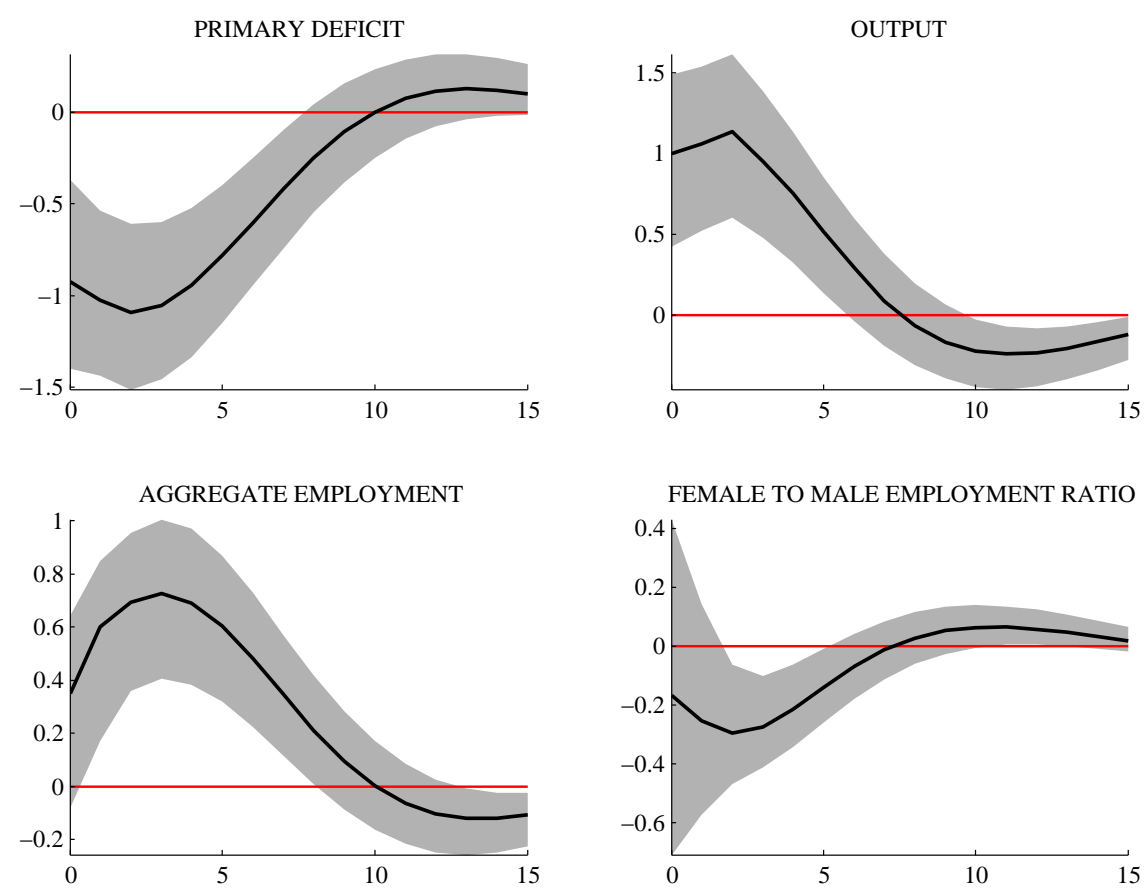

(b) Fiscal shock
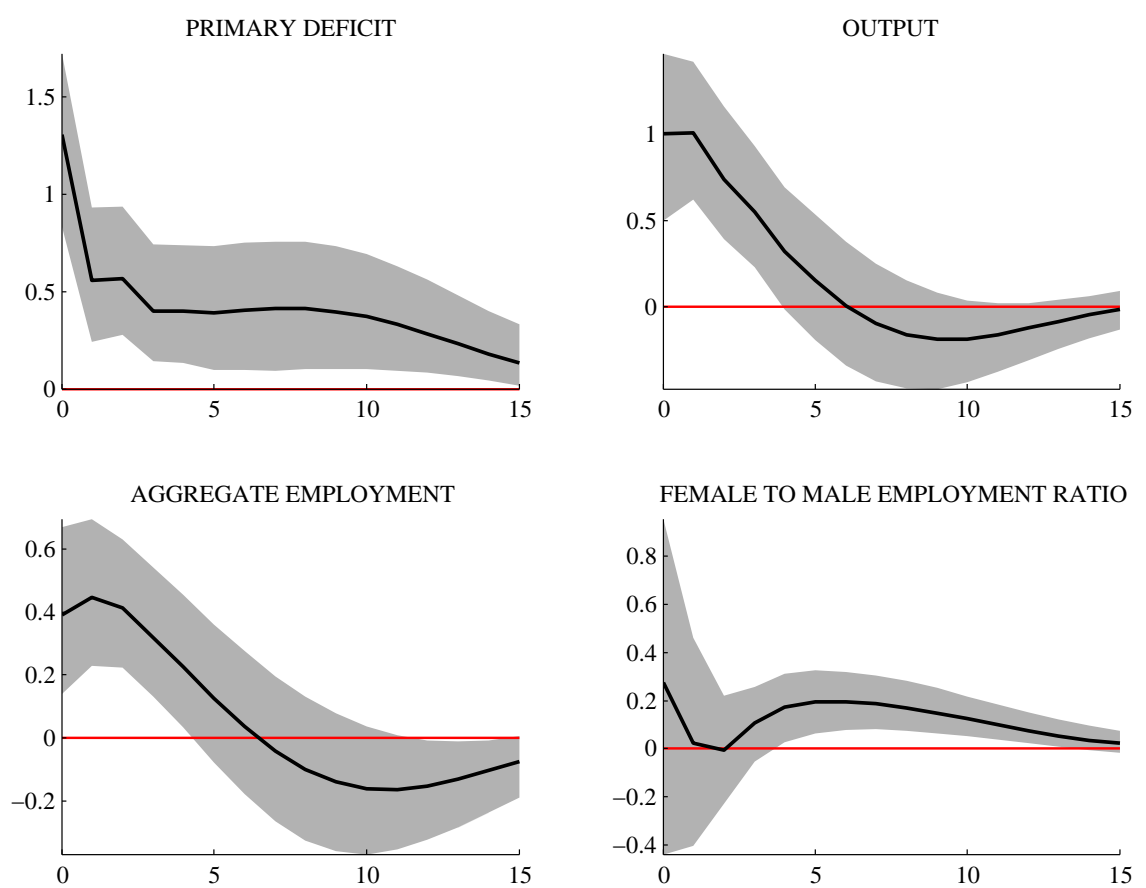

Notes: The solid lines are the median responses and the grey shaded areas show the 16th-84th percentiles of 10,000 estimated responses, sorted at each horizon. The responses are expressed in percentage terms. On the horizontal axes, the horizon is given in quarters. The median impact response of GDP is normalized to one percent. 
fiscal shock, the level of employment has risen by about 250,000 jobs. Of these additional jobs, 156,000 , or $62 \%$, are held by women. We can compare this number to the mean female share in total employment, which is $44 \%$ in our sample. If $44 \%$ of the additional jobs were held by women, the gender composition of employment would remain unchanged. Hence, the female share of jobs created in response to a fiscal shock exceeds this composition-neutral share by 18 percentage points. To demonstrate the importance of this difference, consider the relative growth rates of female and male employment triggered by the fiscal shock. Relative to about 46 million employed women on average, the 156,000 created jobs correspond to $0.32 \%$ whereas, for men, this number is $0.15 \%$. Thus, fiscal expansions cause employment growth which is more than twice as strong for women than for men.

In order to quantify the conditional cyclicality of the gender employment ratio, we compute the correlations of GDP or aggregate employment, respectively, with the gender employment ratio, conditional on the two shocks. Conditional on the non-fiscal shock, the female to male employment ratio has strong negative correlations with GDP and aggregate employment, with estimated contemporaneous correlation coefficients of -0.99 and -0.91 , respectively. Conditional on the fiscal shock, in contrast, the female to male employment ratio is positively correlated with the business cycle. The conditional contemporaneous correlations with GDP and employment are 0.27 and 0.19 , respectively. We find even stronger positive correlations of the gender employment ratio with lags of GDP and employment. For example, the correlation coefficient of the employment ratio with the four-quarter lag of GDP (employment) is $0.78(0.76)$.

Our findings imply that fiscal policy makers are confronted with a trade-off dilemma. Fiscal policy that stabilizes employment destabilizes its gender composition. A contractionary non-fiscal shock causes a man-cession: aggregate employment falls and the employment of men falls disproportionately. If fiscal policy reacts to this and boosts aggregate employment, more women than men are brought into jobs which amplifies the reaction of the gender employment ratio. Hence, our results suggest that fiscal policy which aims to stabilize the level of employment along with its composition achieves only one of these goals.

We have performed a series of robustness checks for our baseline results (details can be found in Appendix B). Our results are robust to: i) including a set of further control variables, specifically, 
the real interest rate, average hourly earnings, private domestic spending, government spending, and tax revenues, ii) shortening the number of periods for which the sign restrictions are imposed, iii) relaxing the restriction that the fiscal shock raises aggregate employment, and iv) starting the sample in 1979, which is the starting date of the Merged Outgoing Rotation Groups (MORG) files of the CPS that will be used in the next section to explore potential explanations for the rise in the gender employment ratio after a fiscal expansion. In each of these specifications, the female to male employment ratio reacts negatively to expansionary non-fiscal shocks in at least $90 \%$ of the accepted models. Likewise, in at least $90 \%$ of the accepted models, the gender employment ratio reacts positively to expansionary fiscal shocks. Further, we have decomposed the fiscal shock into spending hikes and tax cuts, employing opposite sign restrictions on the response of tax revenues. For both kinds of fiscal shocks, we confirm our main finding that expansionary fiscal shocks foster job growth predominantly for women.

\section{Exploring potential explanations: The role of sectors, occupations, and in- dustries}

In this section, we investigate potential explanations for our finding that fiscal shocks lead to a stronger increase in female than in male employment. Specifically, we investigate in how far the documented responses of the gender employment ratio are consequences of the different mean gender employment ratios in different sectors, industries, and occupations. If employment in female-dominated occupations (so-called "pink-collar" occupations, such as personal services) or industries (for instance, education and health care) reacts differently to fiscal shocks, the aggregate gender employment ratio would change even if the gender ratio within occupations and industries remained unchanged. Similar composition effects may occur with respect to government employment, where women constitute the majority of the workforce. Investigating these issues requires data on industry and occupation specific employment by demographic groups. As Hoynes, Miller, and Schaller (2012), we construct disaggregated employment time series using the Merged Outgoing Rotation Groups (MORG) files of the Current Population Survey (CPS). Using this source of data, consistent employment time series can be constructed from 1979 onwards. $^{8}$

\footnotetext{
${ }^{8}$ The sample period for our baseline estimations discussed in Section 2 started in 1964. In Appendix B, we show that the results for our baseline specification estimated from data starting in 1979 are very similar to the results discussed in Section 2. We also checked that aggregating the CPS MORG microdata yields virtually identical time series data
} 
Government employment. The government wage bill is a major part of government consumption expenditures and women are over-represented in government employment. ${ }^{9}$ Therefore, the gender employment ratio may react to fiscal shocks because government employment is expanded.

To investigate the role of government employment, we decompose the dynamics of the aggregate gender employment ratio into the dynamics of gender employment ratios within sectors and the employment dynamics between sectors. Specifically, we estimate a VAR where we include the government to non-government employment ratio, the gender employment ratio in government employment, and the gender employment ratio in private (non-government) employment (next to the budget deficit, real GDP, and aggregate employment, as in our baseline VAR). This specification allows us to disentangle a composition effect (i.e., an increase in government employment relative to non-government employment) from changes within sectors (i.e., changes in the gender ratios within the government and non-government sector, respectively). Otherwise, the specification of the VAR is identical to our baseline model in Section 2.

Figure 2 summarizes the results for the three employment variables discussed above (the responses of the remaining variables are very similar as in the baseline model). In response to non-fiscal shocks, we observe a drop in the ratio of government employment to non-government employment, which is to be expected for a non-fiscal shock, see the left panel in Figure 2(a). Moreover, we observe a drop in the female to male ratio in non-government employment, see the right panel in Figure 2(a). These findings show that man-cessions take place predominantly in the private sector.

Most interestingly, for the non-fiscal shock, we observe a combination of composition effects and within-sector effects. Figure 2(b) shows that the increase in the aggregate gender employment ratio documented in Section 2 stems from a rise in both the ratio of government to non-government employment, see the left panel in Figure 2(b), and in the female to male ratio in private (nongovernment) employment, see the right panel in Figure 2(b). That is, one reason for the stronger employment effects of fiscal policy on women is a composition effect with respect to government employment, which is a sector where women are over-represented. This effect is enforced by the as published by the BLS.

${ }^{9}$ In our CPS MORG sample, the female share in government employment is about $55 \%$, while it amounts to about $46 \%$ in total employment. 
Figure 2: Impulse responses in VAR decomposing the dynamics of the gender employment ratio into between-sectors dynamics and within-sector dynamics.

(a) Non-fiscal shock
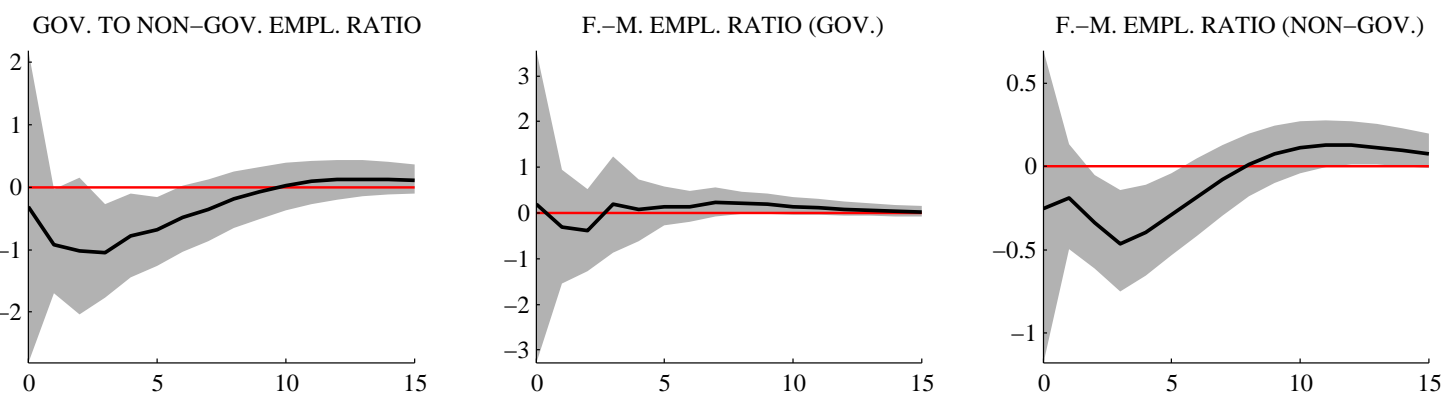

(b) Fiscal shock
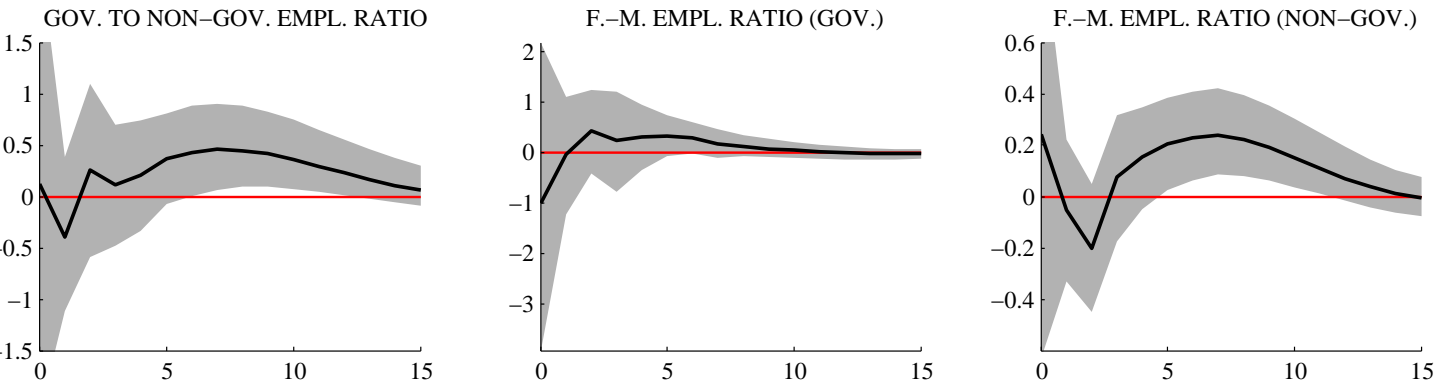

Notes: The solid lines are the median responses and the grey shaded areas show the 16th- 84 th percentiles of 10,000 estimated responses, sorted at each horizon. The responses are expressed in percentage terms. On the horizontal axes, the horizon is given in quarters. The median impact response of GDP (not shown) is normalized to one percent.

fact that, after a fiscal shock, employment of women rises disproportionately to that of men also within the private (non-government) sector, see the right panel in Figure 2(b). ${ }^{10}$

Quantitatively, our results suggest that the composition effect with respect to government employment is moderate. To illustrate this point, we conduct a similar back-of-the-envelope calculation as in the previous section, based on median responses one year after the shock. After a fiscal shock, $37.8 \%$ of the additional jobs are created in the government sector. If we assume, counterfactually, that the gender shares within sectors remain constant, it results that $48.0 \%$ of the total number of new jobs created in both, the government and non-government sectors, would accrue to women. ${ }^{11}$ This is about 2.5 percentage points larger than the share of new jobs created

${ }^{10}$ Interestingly, we do not find significant gender differences in the employment reaction within the public sector (see the middle panel in Figure 2(b)). The government tends to expand its workforce more or less in its initial gender proportions.

${ }^{11}$ This number is calculated as the share of government employment in new jobs (37.8\%) times female share in government employment (54.7\%) plus share of non-government employment in new jobs $(62.2 \%)$ times female share in non-government employment (44.0\%). 
for women that would leave the gender composition of total employment unchanged. ${ }^{12}$ Our results show that a more substantial part is to be attributed to developments within non-government (private) employment, where women's employment rises relative to that of men.

A potential reason for the larger increase in female relative to male employment is that the government mostly purchases goods and services produced in industries where women are employed disproportionately, such as education and health care. However, two of our findings qualify this view. First, we find similar gender employment effects not only for spending hikes, but also for tax cuts, see Appendix B. Second, we will show that industries appear to be less important than occupations for the gender employment effects created by fiscal expansions.

Occupations. Next, we investigate in how far occupation effects are responsible for our finding that fiscal policy shocks foster job growth primarily for women. For instance, during the recovery after the Great Recession, traditionally female-dominated occupations have played an important role. In fact, some commentators have used the term "pink-collar job boom" in this context. ${ }^{13}$ To evaluate the role of occupations for our results, we distinguish between female-dominated ("pinkcollar") occupations and other ("non-pink-collar") occupations, respectively. ${ }^{14}$

In the CPS MORG data, we classify an occupation as a pink-collar occupation if the average female employment share is at least $60 \%$. The so-defined pink-collar occupations range from archivists (female share $60.4 \%$ ) to dental hygienists (98.6\%), a full list can be found in Appendix A. In our sample used in the VAR analysis, $32.5 \%$ of individuals have occupations which we classify as pink-collar occupations. In these "pink" occupations, the female employment share is $82.9 \%$ while it is only $27.5 \%$ in the remaining occupations, which we classify as "non-pink".

Figure 3 shows the results for a specification where we decompose the response of the aggregate gender employment ratio by including the ratio of employment in pink-collar occupations to employment in non-pink-collar occupations (to measure composition effects), as well as the two gender employment ratios within pink-collar occupations and within non-pink-collar occupations,

\footnotetext{
${ }^{12}$ In the sample starting in 1979 , the composition-neutral share, which corresponds to the average share of female employment in total employment, is $45.6 \%$.

${ }^{13}$ See, e.g., David Francis' contribution in U.S. News (Sep. 10, 2012).

${ }^{14}$ We follow Autor and Dorn (2013) in constructing 332 occupation categories in the CPS MORG data which are consistently defined over the whole sample. Their classification system provides a balanced panel of occupations covering the 1980, 1990, and the 2000 Census classifications by mapping Census occupation codes to a unified category system.
} 
Figure 3: Impulse responses in VAR decomposing the dynamics of the gender employment ratio into between-occupations dynamics and within-occupation dynamics.

(a) Non-fiscal shock
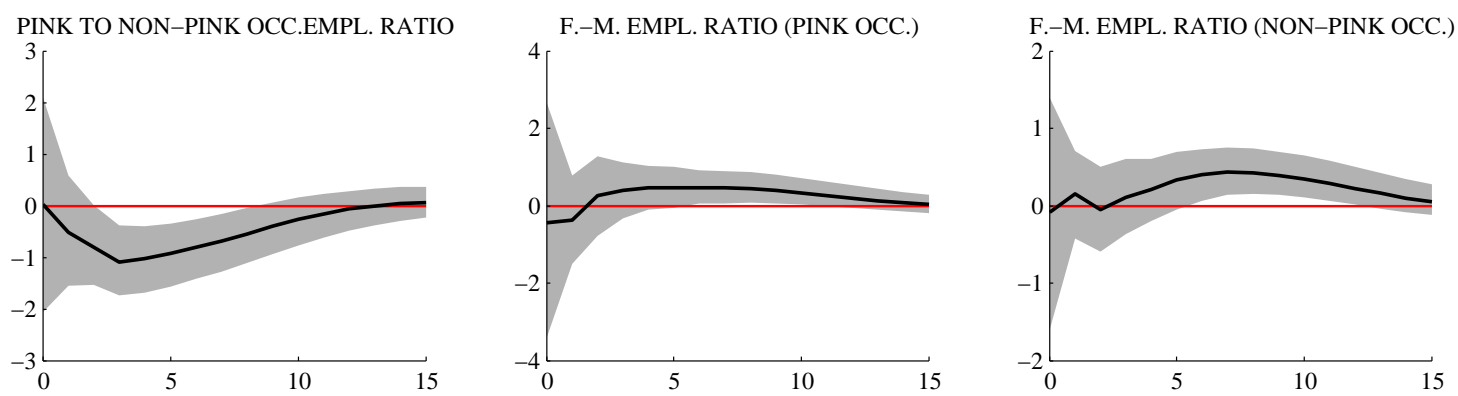

(b) Fiscal shock
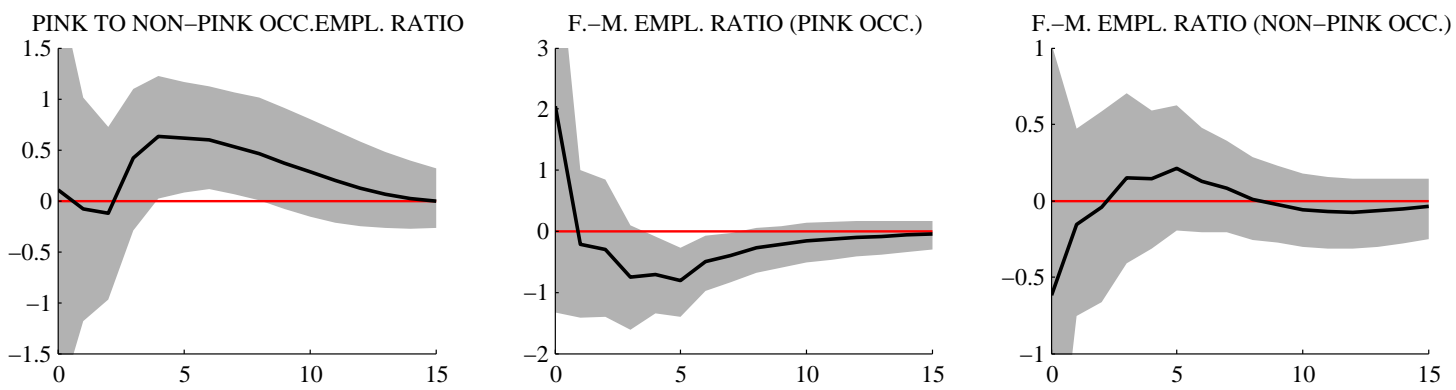

Notes: The solid lines are the median responses and the grey shaded areas show the 16th- 84 th percentiles of 10,000 estimated responses, sorted at each horizon. The responses are expressed in percentage terms. On the horizontal axes, the horizon is given in quarters. The median impact response of GDP (not shown) is normalized to one percent.

respectively. ${ }^{15}$

Panel (a) shows that, in response to expansionary non-fiscal shocks, employment in non-pinkcollar occupations rises disproportionately. This indicates that occupations play a role in explaining man-cessions. But we also observe substantial reactions of the gender employment ratio within occupation groups, particularly within non-pink-collar occupations.

Occupations play a major role for the employment effects of fiscal policy by gender. The left panel in Figure 3(b) shows that fiscal expansions trigger a pink-collar job boom, i.e. employment in female-dominated occupations rises more strongly than employment in other occupations. This raises the aggregate gender employment ratio by construction since women are over-represented in pink-collar occupations. Interestingly, we do not observe a significant change in the gender employment ratio in non-pink-collar occupations, see the right panel in Figure 3(b). Note that

\footnotetext{
${ }^{15} \overline{\text { In this specification, the sample ends in 2010Q4 }}$ since there was another major change in the occupational classification system in 2011.
} 
there is even a significant reduction in the female-to-male employment ratio within pink-collar occupations. Apparently, fiscal expansions induce men to pick up jobs in traditionally femaledominated occupations. ${ }^{16}$

Within neither of the two occupation groups, female employment rises relative to male employment. This means that the composition effect with respect to occupations, visible in the left panel of Figure 3(b), is driving the female-biased employment effects of fiscal policy in the aggregate. Quantitatively, the composition effect is rather important. When gender shares within occupations remained constant, the median responses one year after the shock would imply that roughly all of the additional jobs accrue to women. ${ }^{17}$ However, the actual female share of additional jobs is smaller since the share of men in pink-collar occupations increases.

Industries. To complement the analysis, we now investigate the role of industry effects. The CPS MORG data allows us to construct 195 industry classifications which are consistently defined over the whole sample. We categorize an industry as female-dominated if the average share of women in this industry is at least $60 \%$. The female-dominated industries range from hotels and motels (female share $61.1 \%$ ) to dressmaking shops (96.5\%), a full list can be found in Appendix A. For simplicity, we refer to female-dominated industries as "pink" and to non-female-dominated industries as "non-pink" industries. ${ }^{18}$

Figure 4 summarizes the results from a specification where we decompose the aggregate gender employment ratio into a between-industry component and two within-industry components. Figure 4(a) shows that industries play a major role for understanding man-cessions. The ratio of employment in female-dominated industries to employment in other industries is counter-cyclical in response to non-fiscal shocks, indicating that employment in female-dominated industries is less cyclical than employment in other industries. This is generally in line with the results of Hoynes, Miller, and Schaller (2012) who consider employment cyclicality by gender and industry without distinguishing between drivers of the business cycle.

\footnotetext{
${ }^{16}$ Bansak, Graham, and Zebedee (2012) have documented that the gender desegregation of occupations is accelerated in upswings, which is in line with our results.

${ }^{17}$ Share of pink-collar occupations in new jobs (132.3\%) times female share in pink-collar occupations (82.9\%) plus share of non-pink-collar occupations in new jobs (-32.3\%) times female share in non-pink-collar occupations $(27.5 \%)$ $=100.8 \%$.

${ }^{18}$ Note that our interest lies on the industry mix of the created jobs rather than on the industry mix of the goods and services purchased by the government.
} 
Figure 4: Impulse responses in VAR decomposing the dynamics of the gender employment ratio into between-industry dynamics and within-industry dynamics.

(a) Non-fiscal shock
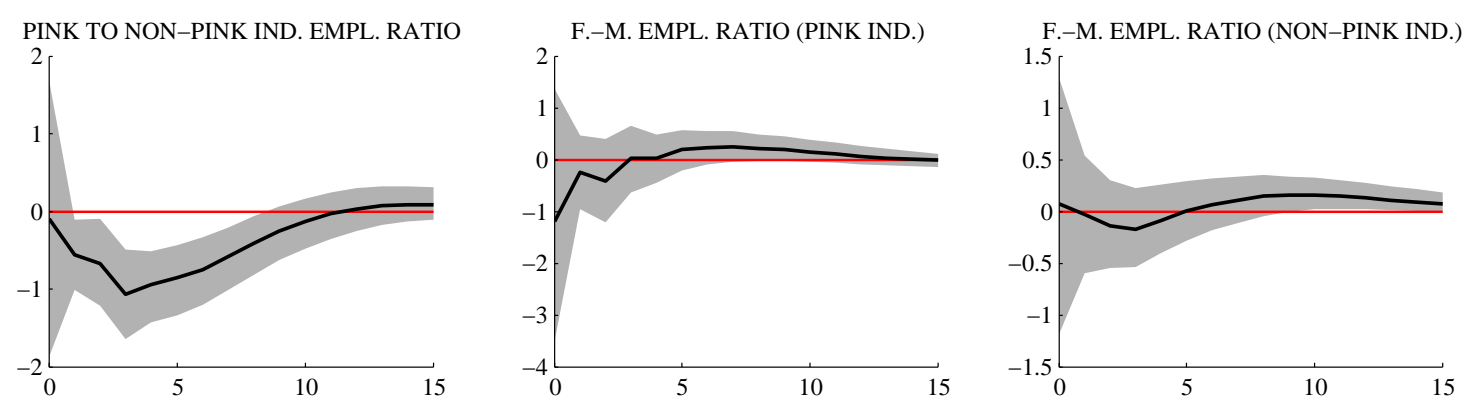

(b) Fiscal shock
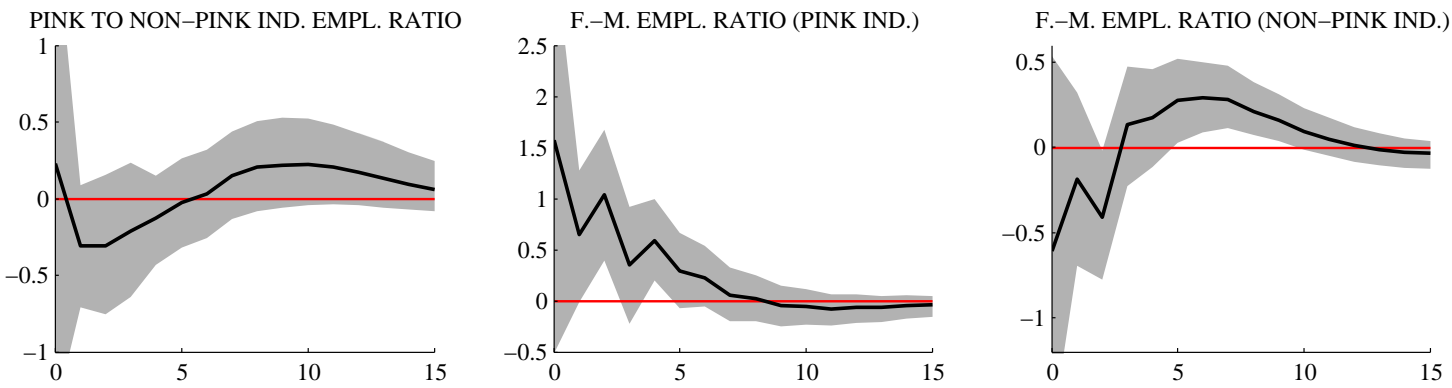

Notes: The solid lines are the median responses and the grey shaded areas show the 16th-84th percentiles of 10,000 estimated responses, sorted at each horizon. The responses are expressed in percentage terms. On the horizontal axes, the horizon is given in quarters. The median impact response of GDP (not shown) is normalized to one percent.

While we documented in the previous subsection that occupation effects are important for understanding the employment effects of fiscal policy by gender, Figure 4(b) shows that effects at the industry level are much less important in this respect. In fact, after fiscal shocks, we do not observe substantial variation in between-industry employment, but, rather, there are substantial changes in the gender composition within industry groups. ${ }^{19}$

Discussion. All in all, the results documented in this section suggest that the effects of fiscal policy on the gender composition of employment are mainly due to fiscal expansions fostering job creation foremost in female-dominated (pink-collar) occupations. Further, we have shown that the disproportionate employment gains of women do not reflect pure composition effects stemming from the industry mix of the created jobs. In fact, the gender employment ratio is also affected within industries, as shown above. We now take a comprehensive view on the evidence presented

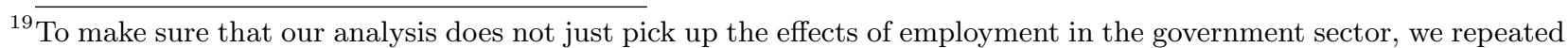
the estimations concerning occupation dynamics and industry dynamics using private (non-government) employment only. We find very similar results when we restrict the data to private employment, see Appendix B. 
above and briefly discuss three potential interpretations of the documented occupational dynamics.

First, the overall patterns documented in this paper are consistent with a production technology that implies different output sensitivities of labor demand across occupations. As an example, consider a kindergarten facing an increase in the demand for child care. Most likely, the kindergarten will demand more services of kindergarten teachers (a typical pink-collar occupation) but it is less clear that it will also hire additional caretakers (a typical non-pink-collar occupation). As a second example, consider a car producing firm facing a demand peak. At least some of the additional cars can be produced by raising capital utilization or can be supplied from inventories. As a consequence, the firm's demand for assembly line workers (a typical non-pink-collar occupation) is likely to rise less than proportionally with demand. By contrast, office services can neither easily be produced using capital nor stored such that the firm is likely to raise its demand for office and managerial employees (pink-collar occupations) more or less proportionally with output. Thus, labor in pink-collar occupations may rise hand in hand with output within industries or firms, whereas non-pink-collar labor may rise less than proportionally with output.

A second interpretation rests on the differential importance of firm-specific human capital in different occupations. Firm-specific human capital is known to make firms reluctant to adjust labor input along the extensive margin since, e.g., hirings are associated with training costs. If firm-specific human capital is less important in personal-service occupations (which are typical pink-collar occupations), this would induce employment in these occupations to rise relatively more strongly when total labor demand is expanded. ${ }^{20}$

A third interpretation is related to what the management literature has labeled the servitization of products (e.g., Kastalli and Looy 2013). Servitization of products means that certain products have a higher service component today than in the past. If such change takes the form of entering products having higher service components than incumbent products, the pro-cyclicality of product entry and innovation in general, as shown by, e.g., Fabrizio and Tsolmon (2014), can explain why, in response to demand expansions, employment in pink-collar (mostly service-oriented) occupations tends to increase more strongly than in non-pink-collar occupations. While this is in line with what we found empirically, one would expect similar developments also for the economy's industry

\footnotetext{
${ }^{20}$ For instance, Kwon and Meyersson Milgrom (2014) provide empirical evidence that the importance of firm-specific human capital varies across occupations.
} 
mix where we found only weak effects.

For expansionary non-fiscal shocks, we have documented that they cause a drop in the pink to non-pink occupation ratio rather than an increase, see Figure 3. At first sight, this does not seem to square with the interpretations discussed above which, in principle, also apply for expansionary non-fiscal shocks. Yet, the results also show that non-fiscal shocks cause employment in non-pink, male-dominated, industries to rise disproportionately, see Figure 4. This lowers the economy-wide pink to non-pink occupation ratio via a composition effect since female-dominated industries also employ a large share of pink-collar workers.

\section{Conclusion}

We have estimated VAR models and identified the employment effects of fiscal and non-fiscal shocks by gender using sign restrictions. Contractionary non-fiscal shocks lead to man-cessions, i.e. to disproportionate job losses for men. Our main result is that a fiscal stimulus leads to a disproportionate surge in the employment of women relative to that of men. Taken together, this implies a trade-off dilemma for fiscal policy that aims to stabilize the level of employment along with its composition. Men are hit hardest in recessions but a fiscal stimulus predominantly fosters job creation for women.

We have performed a number of additional evaluations in order to explore potential explanations for our results. One reason for the disparate gender effects of fiscal policy is the expansion of government employment, but its quantitative importance is limited. The gender-specific employment effects of fiscal policy are mainly explained by the dynamics of occupational employment, whereas industry effects matter less. By contrast, industry dynamics are important for understanding why man-cessions occur in the first place. 


\section{References}

Autor, D. and D. Dorn (2013). The growth of low skill service jobs and the polarization of the U.S. labor market. American Economic Review 103(5), 1553-1597.

Bansak, C., M. E. Graham, and A. A. Zebedee (2012). Business cycles and gender diversification: An analysis of establishment-level gender dissimilarity. American Economic Review: Papers E Proceedings 102(3), 561565.

Canova, F. and E. Pappa (2007). Price differentials in monetary unions: The role of fiscal shocks. Economic Journal 117(520), 713-737.

Clark, K. B. and L. H. Summers (1981). Demographic differences in cyclical employment variation. Journal of Human Resources 16(1), 61-79.

Contessi, S. and L. Li (2014). Around the world, gender gaps ebb and flow. St. Louis Fed, The Regional Economist (January), 10-11.

Elsby, M. W., B. Hobijn, and A. Şahin (2010). The labor market in the Great Recession. Brookings Papers on Economic Activity 41, 1-69.

Enders, Z., G. J. Müller, and A. Scholl (2011). How do fiscal and technology shocks affect real exchange rates?: New evidence for the United States. Journal of International Economics 83(1), 53-69.

Ewing, B., W. Levernier, and F. Malik (2005). Modeling unemployment rates by race and gender: A nonlinear time series approach. Eastern Economic Journal 31(3), 333-347.

Ewing, B. T., W. Levernier, and F. Malik (2002). The differential effects of output shocks on unemployment rates by race and gender. Southern Economic Journal 68(3), 584-599.

Fabrizio, K. R. and U. Tsolmon (2014). An empirical examination of the procyclicality of R\&D investment and innovation. Review of Economics and Statistics 96(4), 662-675.

Giavazzi, F. and M. McMahon (2012). The household effects of government spending. In Fiscal Policy after the Financial Crisis, NBER Chapters, pp. 103-141. National Bureau of Economic Research, Inc.

Hoynes, H., D. L. Miller, and J. Schaller (2012). Who suffers during recessions? Journal of 
Economic Perspectives 26(3), 27-48.

Jefferson, P. N. (2005). Does monetary policy affect relative educational unemployment rates? American Economic Review 95(2), 76-82.

Jefferson, P. N. (2008). Educational attainment and the cyclical sensitivity of employment. Journal of Business and Economic Statistics 26(4), 526-535.

Kastalli, I. V. and B. V. Looy (2013). Servitization: Disentangling the impact of service business model innovation on manufacturing firm performance. Journal of Operations Management 31(4), 169-180.

Kwon, I. and E. M. Meyersson Milgrom (2014). The significance of firm and occupation specific human capital for hiring and promotions. Labour Economics 31, 162-173.

Pappa, E. (2009). The effects of fiscal shocks on employment and the real wage. International Economic Review 50(1), 217-244.

Rodgers, W. M. (2008). African American and white differences in the impacts of monetary policy on the duration of unemployment. American Economic Review 98(2), 382-386.

Uhlig, H. (2005). What are the effects of monetary policy on output? Results from an agnostic identification procedure. Journal of Monetary Economics 52(2), 381-419.

Wall, H. J. (2009). The "man-cession" of 2008-09: It's big, but it's not great. St. Louis Fed, The Regional Economist (October), 6-9. 


\section{A Data appendix}

\section{A.1 Data sources and definitions}

Table A1: Data sources

\begin{tabular}{lll}
\hline Series Title & Series ID & Source \\
\hline Civilian Noninstitutional Population & CNP16OV & BLS \\
Civilian Employment-Population Ratio & EMRATIO & BLS \\
Employment-Population Ratio - Women & LNS12300002 & BLS \\
Employment-Population Ratio - Men & LNS12300001 & BLS \\
Government Current Expenditures: Interest Payments & A180RC1Q027SBEA & BEA \\
Gross Domestic Product & GDP & BEA \\
Gross Domestic Product: Implicit Price Deflator & GDPDEF & BEA \\
Net Government Saving _-- - - - - - - - - - - - - - - - - - - - - - - - - - - - - - --- \\
Average Hourly Earnings of Production and Nonsupervisory & AHEPTI & BLS \\
Employees: Total Private & W054RC1Q027SBEA & BEA \\
Current Tax Receipts & FEDFUNDS & BFED \\
Effective Federal Funds Rate & A955RC1Q027SBEA & BEA \\
Government Consumption Expenditures & A782RC1Q027SBEA & BEA \\
Gross Government Investment & GPDI & BEA \\
Gross Private Domestic Investment & PCE & BEA \\
Personal Consumption Expenditures & &
\end{tabular}

Notes: BLS: U.S. Bureau of Labor Statistics, BEA: U.S. Bureau of Economic Analysis, BFED: Board of Governors of the Federal Reserve System.

Table A2: Definition of variables

\begin{tabular}{|c|c|c|}
\hline Variable & Definition & Description \\
\hline Primary Deficit & $\mathrm{hp}\left(\frac{-(T G D E F+A 180 R C 1 Q 027 S B E A)}{\operatorname{mean}(G D P)}\right)$ & $\begin{array}{l}\text { cyclical component of real primary gov- } \\
\text { ernment deficit relative to average GDP }\end{array}$ \\
\hline Output & $\operatorname{hp}\left(\log \left(\frac{(G D P)}{(G D P D E F) \cdot(C N P 16 O V)}\right)\right)$ & $\begin{array}{l}\text { cyclical component of log real GDP per } \\
\text { capita }\end{array}$ \\
\hline Aggregate Employment & $\mathrm{hp}(\log (E M R A T I O))$ & $\begin{array}{l}\text { cyclical component of log aggregate } \\
\text { employment }\end{array}$ \\
\hline Female-male Employment Ratio & $\mathrm{hp}\left(\log \left(\frac{L N S 12300002}{L N S 12300001}\right)\right)$ & $\begin{array}{l}\text { cyclical component of log employment } \\
\text { ratio between women and men }\end{array}$ \\
\hline Government Spending & $\operatorname{hp}\left(\log \left(\frac{(A 955 \ldots)+(A 782 \ldots)}{G D P D E F \cdot C N P 16 O V}\right)\right)$ & 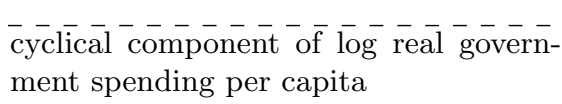 \\
\hline Tax Revenues & $\mathrm{hp}\left(\log \left(\frac{W 054 R C 1 Q 027 S B E A}{G D P D E F \cdot C N P 16 O V}\right)\right)$ & $\begin{array}{l}\text { cyclical component of log real govern- } \\
\text { ment tax revenues per capita }\end{array}$ \\
\hline Real interest rate & $\mathrm{hp}\left(\frac{F E D F U N D S}{100}-\log \left(\frac{G D P D E F(+1)}{G D P D E F}\right) \cdot 4\right)$ & $\begin{array}{l}\text { cyclical component of annualized real } \\
\text { interest rate }\end{array}$ \\
\hline Private Domestic Spending & $\operatorname{hp}\left(\log \left(\frac{(P C E+G P D I)}{(G D P D E F) \cdot(C N P 16 O V)}\right)\right)$ & $\begin{array}{l}\text { cyclical component of log real private } \\
\text { domestic spending }\end{array}$ \\
\hline Hourly Earnings & $\mathrm{hp}\left(\log \left(\frac{A H E P T I}{G D P D E F}\right)\right)$ & $\begin{array}{l}\text { cyclical component of log real hourly } \\
\text { earnings }\end{array}$ \\
\hline
\end{tabular}

Notes: The function hp stands for Hodrick-Prescott (HP) filter using a smoothing parameter of 1600 . $(+1)$ indicates a one-quarter lead. 


\section{A.2 Occupation and industry classifications in the CPS-MORG}

The CPS is a representative monthly household survey conducted by the U.S. Bureau of Labor Statistics, covering a number of demographic and labor-market related questions. The Merged Outgoing Rotation Group (MORG) is a subset of the full CPS sample (25,000 or more individuals per month) and can be downloaded from the National Bureau of Economic Research: http://www.nber.org/morg/annual/.

We checked that aggregating the monthly CPS-MORG micro data to quarterly, seasonally adjusted time series yields virtually identical time series as published by the BLS. We include individuals aged 16 and over and use the CPS Earnings Weight when collapsing the micro data. The CPS Labor Force Status variable is used to classify individuals as working. In the evaluations using occupation-specific or industry-specific employment data, we drop observations with missing information on these variables. Below, we provide the lists of occupations and industries that we classify as "pink", i.e., female-dominated. The share of female workers is provided in parentheses.

Occupations. Female-dominated occupations are Archivists and curators (60.6\%), Psychologists $(60.8 \%)$, Personal service occupations, n.e.c. (61.4\%), Human resources and labor relations managers (62.1\%), Respiratory therapists (62.5\%), Batch food makers (63.0\%), Computer and peripheral equipment operators (64.0\%), Office machine operators, n.e.c. (64.3\%), Packers, fillers, and wrappers (64.4\%), Vocational and educational counselors (65.6\%), Animal caretakers, except farm (65.6\%), Door-to-door sales, street sales, and news vendors (65.9\%), Teachers, n.e.c. (66.1\%), Dental laboratory and medical appliance technicians (66.2\%), Packers and packagers by hand (66.5\%), Human resources clerks, excluding payroll and timekeeping (66.5\%), Other telecom operators (66.7\%), Supervisors of personal service jobs, n.e.c. (66.8\%), Personnel, HR, training, and labor relations specialists (66.9\%), Supervisors of food preparation and service (67.6\%), Recreation and fitness workers $(67.8 \%)$, Health technologists and technicians, n.e.c. (67.9\%), Food preparation workers (68.1\%), Crossing guards (68.3\%), Bill and account collectors (68.4\%), Transportation ticket and reservation agents (68.7\%), Laundry and dry cleaning workers (68.7\%), Insurance underwriters $(70.0 \%)$, Office supervisors $(70.4 \%)$, Knitters, loopers, and toppers, textile operatives (71.4\%), Insurance adjusters, examiners, and investigators (71.6\%), Managers of medicine 
and health occupations (72.0\%), Clothing pressing machine operators (72.2\%), Physical therapists (72.3\%), Graders and sorters of agricultural products (72.5\%), Customer service reps, invest., adjusters, excluding insurance (72.5\%), Social workers (72.6\%), Winding and twisting textile and apparel operatives (72.6\%), Hotel clerks (73.6\%), Public transportation attendants and inspectors (73.7\%), Radiologic technologists and technicians (74.5\%), Therapists, n.e.c. (75.0\%), Shoemaking machine operators (76.4\%), Correspondence and order clerks (76.9\%), Clinical laboratory technologies and technicians (77.4\%), Proofreaders (79.0\%), Statistical clerks (79.9\%), Administrative support jobs, n.e.c. (80.0\%), Legal assistants and paralegals (80.3\%), Library assistants (80.5\%), Welfare service workers (80.9\%), Interviewers, enumerators, and surveyors (81.3\%), Management support occupations (81.9\%), Cashiers (82.0\%), Dressmakers, seamstresses, and tailors (82.1\%), Dancers (82.9\%), General office clerks (83.0\%), File clerks (83.5\%), Records clerks (83.7\%), Waiters and waitresses (84.1\%), Primary school teachers (84.6\%), Special education teachers (85.1\%), Librarians (85.6\%), Data entry eyers (85.6\%), Sales demonstrators, promoters, and models (86.2\%), Housekeepers, maids, butlers, and cleaners (86.7\%), Eligibility clerks for government programs, social welfare (87.2\%), Payroll and timekeeping clerks (88.4\%), Billing clerks and related financial records processing (88.9\%), Health and nursing aides (89.2\%), Occupational therapists (90.2\%), Telephone operators (90.4\%), Textile sewing machine operators (90.8\%), Bank tellers (91.1\%), Hairdressers and cosmetologists (91.5\%), Health record technologists and technicians (91.6\%), Dieticians and nutritionists (91.9\%), Speech therapists (92.3\%), Bookkeepers and accounting and auditing clerks (92.4\%), Teacher's aides (93.3\%), Receptionists and other information clerks (94.3\%), Registered nurses (94.3\%), Typists (95.4\%), Child care workers (95.8\%), Licensed practical nurses (95.9\%), Dental Assistants (97.7\%), Kindergarten and earlier school teachers (98.2\%), Secretaries and stenographers (98.4\%), Dental hygienists (98.6\%).

Industries. Female-dominated industries are Hotels and motels (61.1\%), Leather products, except footwear (61.3\%), Insurance (61.7\%), Laundry, cleaning, and garment services $(62.2 \%)$, Membership organizations (62.5\%), Offices of chiropractors (63.9\%), Footwear, except rubber and plastic (64.5\%), Dairy product stores (64.9\%), Personnel supply services (65.2\%), Retail bakeries (65.9\%), Credit agencies, n.e.c., savings and loan associations (66.3\%), Drug stores (66.6\%), Jewelry stores (66.7\%), Educational services, n.e.c., business, trade, and vocational schools (67.2\%), Misc. fabri- 
cated textile products (67.7\%), Department stores and mail order houses (69.7\%), Knitting mills (71.0\%), Banking (71.2\%), Offices of health practitioners, n.e.c., offices of optometrists $(71.6 \%)$, Misc. general merchandise stores and sewing, needlework, and piece good stores (72.3\%), Residential care facilities, without nursing (73.3\%), Lodging places, except hotels and motels (74.6\%), Variety stores (75.5\%), Offices of physicians (75.5\%), Direct selling establishments (75.6\%), Retail florists $(75.6 \%)$, Social services, n.e.c. (75.7\%), Heath services, n.e.c., job training and vocational rehab services (76.3\%), Elementary and secondary schools, child day care services (77.5\%), Hospitals (78.0\%), Offices of dentists (78.6\%), Apparel and accessory stores, except shoe (78.8\%), Apparel and accessories, except knit (79.5\%), Libraries (81.2\%), Private households (87.6\%), Nursing and personal care facilities (87.6\%), Beauty shops (89.6\%), Dressmaking shops (96.5\%). 


\section{B Robustness checks}

Baseline model. Figure A1 summarizes the results from various robustness checks for our main finding that fiscal expansions lead to a disproportionate increase in the employment of women and that contractionary non-fiscal shocks lead to man-cessions. The upper left panels in Figures A1(a) and A1(b) show our baseline specification for the sake of comparison. Our main results are robust to changing the starting date of the sample, to including a set of macroeconomic controls (real interest rate, hourly earnings, and private domestic spending), to including fiscal controls (government spending and tax revenues), to imposing the sign restrictions for two instead of four quarters, and to relaxing the sign restriction on aggregate employment. Note that, in all specifications, the female to male employment ratio reacts negatively to expansionary non-fiscal shocks in at least $90 \%$ of the accepted models. Likewise, in at least $90 \%$ of the accepted models, the ratio reacts positively to expansionary fiscal shocks.

Tax shocks versus spending shocks. Here, we present results for a specification where we decompose the fiscal shock into government spending shocks and tax shocks, respectively. To identify government spending shocks and tax shocks separately, we include tax revenues and government spending as additional variables in the baseline VAR and impose the identifying restrictions discussed in Canova and Pappa (2007). A government spending shock raises spending and tax revenues, whereas an expansionary tax shock reduces tax revenues. In all other respects, the specification is as in the baseline VAR from Section 2. In particular, both fiscal shocks induce a positive co-movement of GDP and the deficit. Figures A2(a) and A2(b) show the responses to a government spending shock and to an expansionary tax shock, respectively. The most important result is that the gender employment ratio increases after both types of fiscal stimuli. The results for the non-fiscal shock are very similar to the baseline VAR, see Figure 1, and are therefore not shown (after a non-fiscal shock, tax receipts increase and government spending does not change significantly).

Occupations and industries. Figures A3 and A4 show the results for a specification where we exclude government employees when collapsing the occupation- and industry specific employment data. The results are qualitatively similar to the ones reported in the main text. 
Figure A1: Impulse responses of the female to male employment ratio in different specifications.

(a) Non-fiscal shock

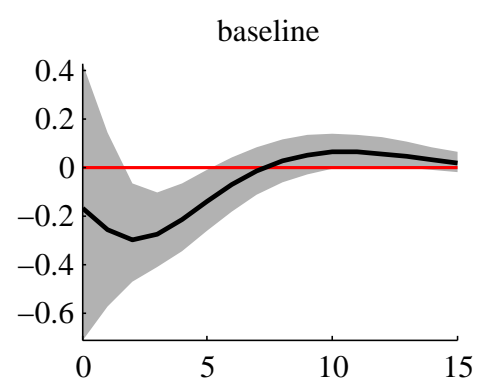

with fiscal controls
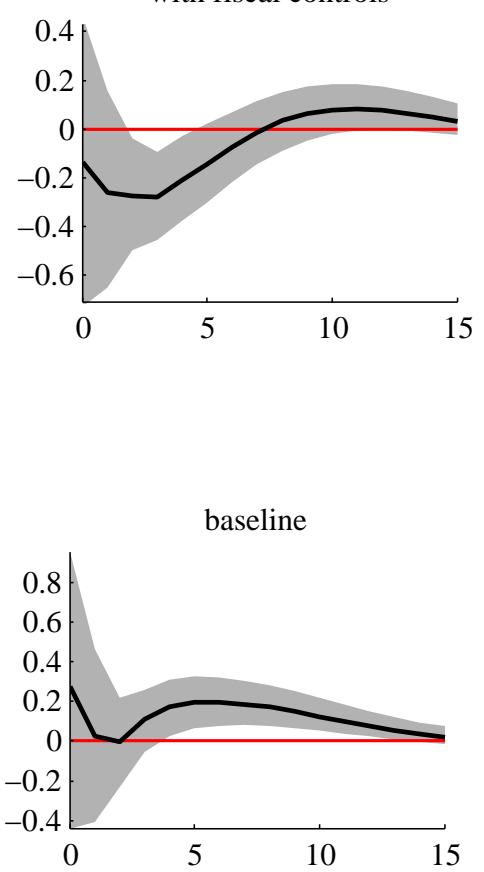

with fiscal controls

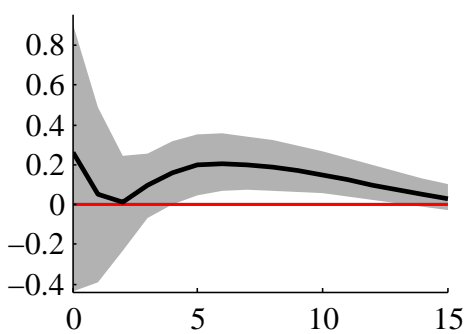

sample 1979-2013

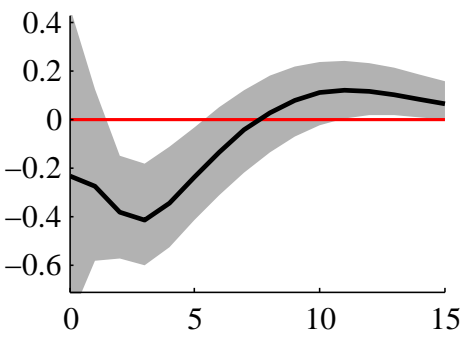

sign restr. for 2 periods

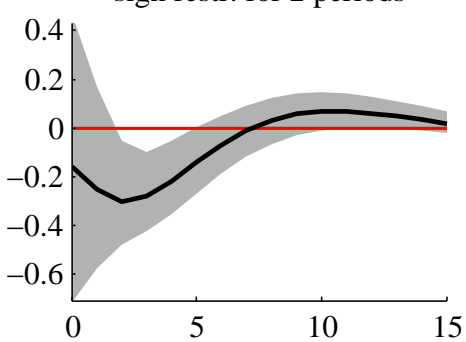

(b) Fiscal shock

sample 1979-2013

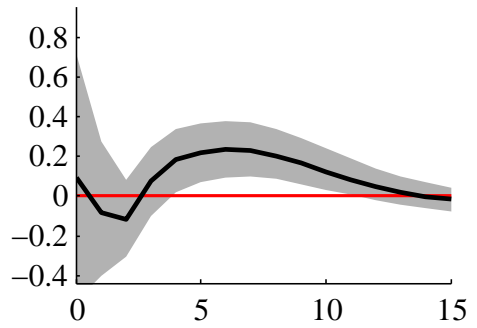

sign restr. for 2 periods

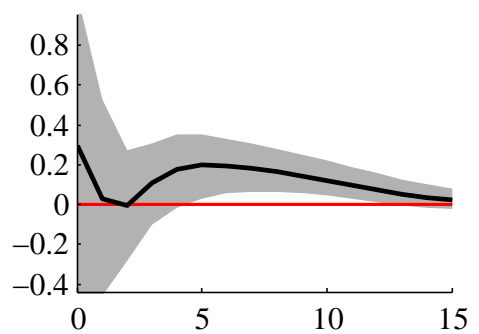

with macro controls

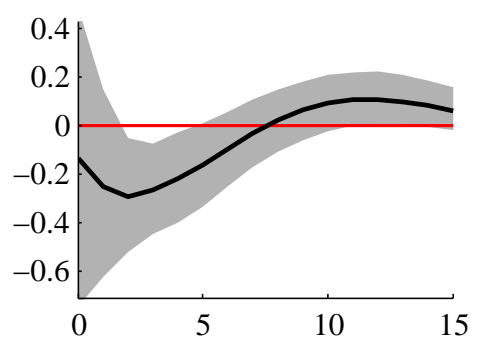

no restr. on agg. emp.

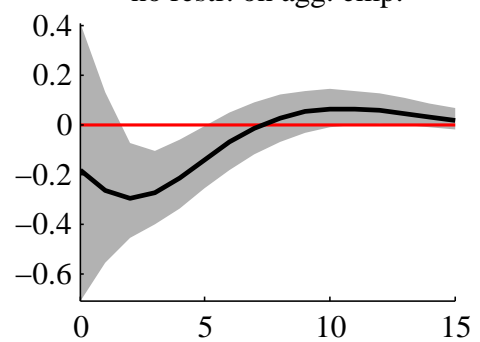

\section{5}

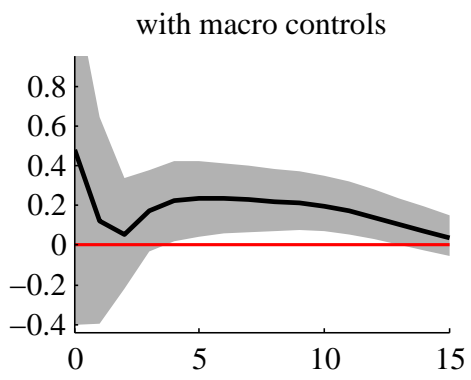

no restr. on agg. emp.

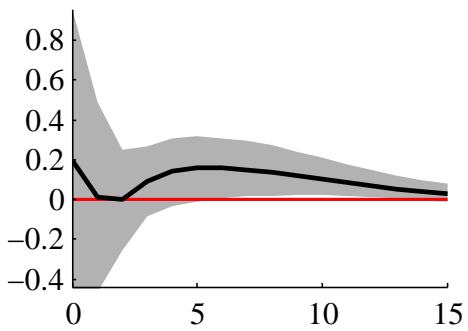

Notes: The solid lines are the median responses and the grey shaded areas show the 16th-84th percentiles of 10,000 estimated responses, sorted at each horizon. The responses are expressed in percentage terms. On the horizontal axes, the horizon is given in quarters. The median impact response of GDP (not shown) is normalized to one percent. 
Figure A2: Impulse responses to tax shocks and spending shocks.

(a) Spending shock
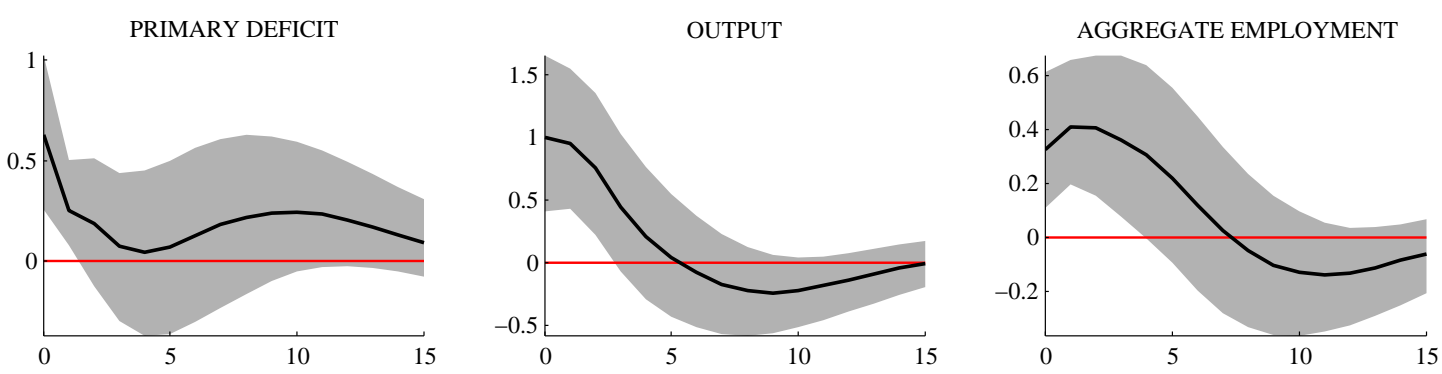

FEMALE TO MALE EMPLOYMENT RATIO

TAX REVENUES
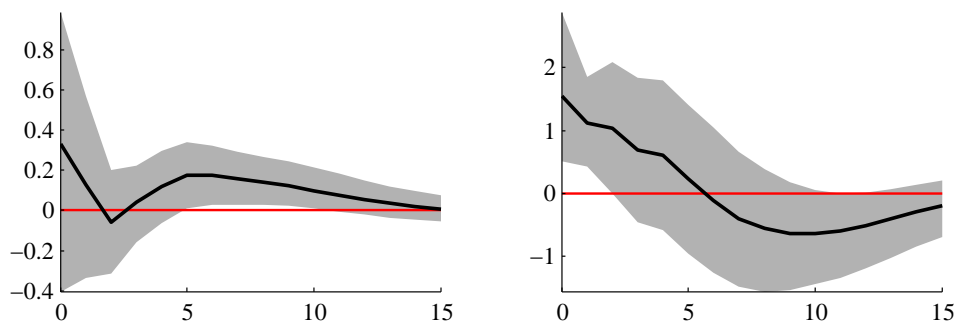

GOVERNMENT SPENDING

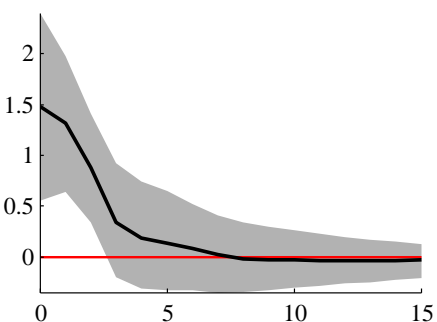

(b) Tax shock
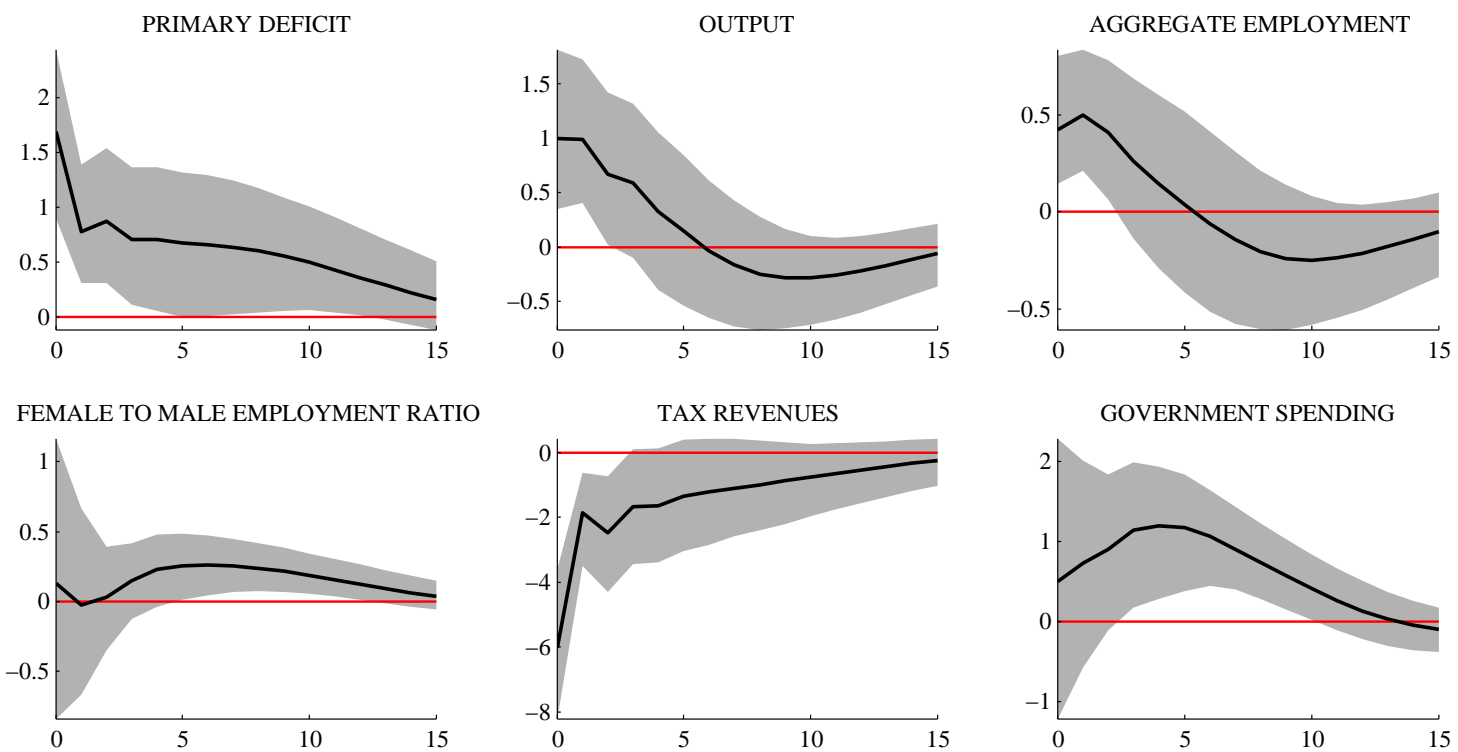

Notes: The solid lines are the median responses and the grey shaded areas show the 16th- 84 th percentiles of 10,000 estimated responses, sorted at each horizon. The responses are expressed in percentage terms. On the horizontal axes, the horizon is given in quarters. The median impact response of GDP (not shown) is normalized to one percent. 
Figure A3: Impulse responses in VAR decomposing the dynamics of the gender employment ratio into between-occupation dynamics and within-occupation dynamics, excluding government employment

(a) Non-fiscal shock
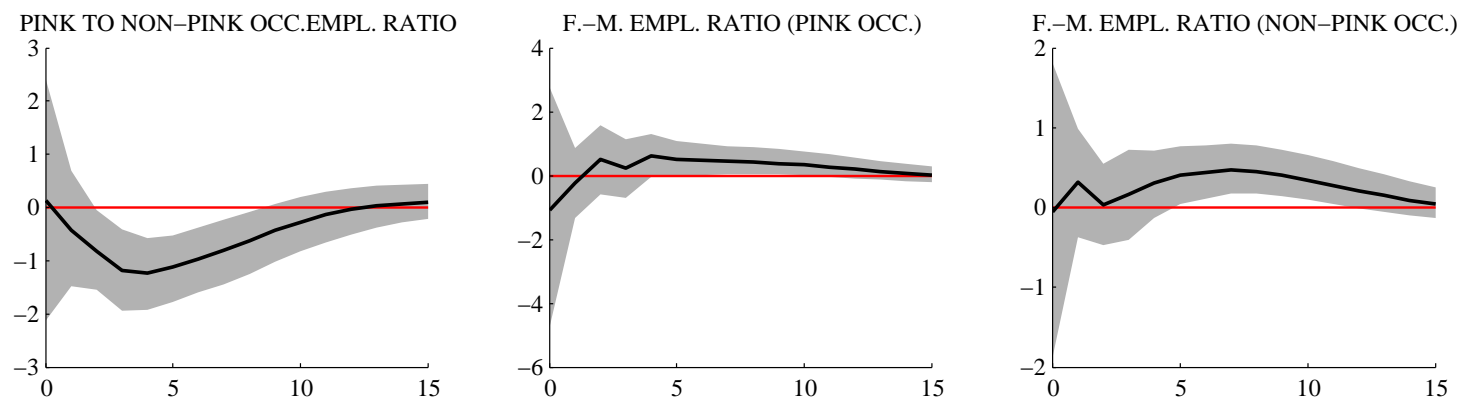

(b) Fiscal shock
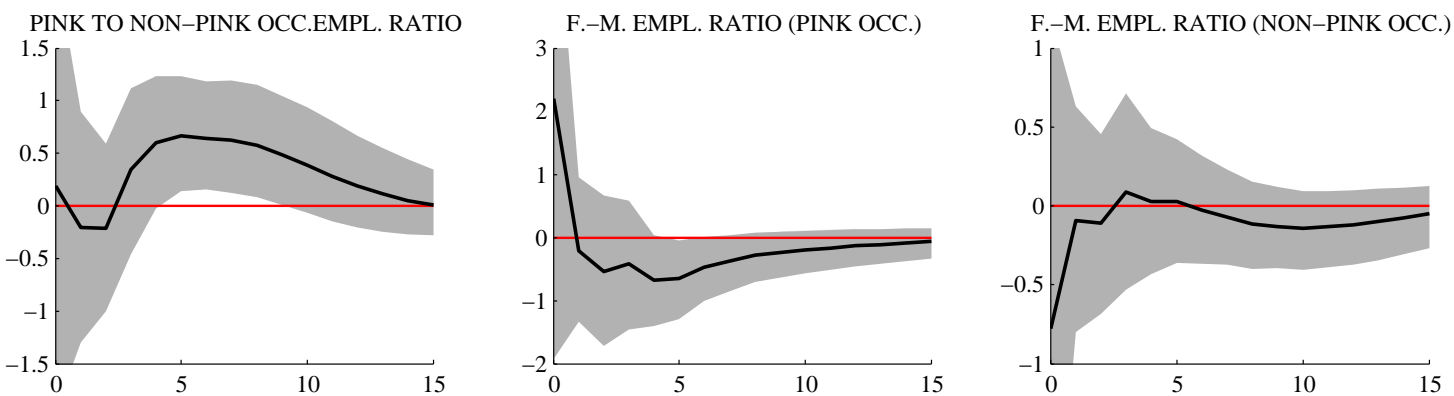

Notes: The solid lines are the median responses and the grey shaded areas show the 16th-84th percentiles of 10,000 estimated responses, sorted at each horizon. The responses are expressed in percentage terms. On the horizontal axes, the horizon is given in quarters. The median impact response of GDP (not shown) is normalized to one percent. 
Figure A4: Impulse responses in VAR decomposing the dynamics of the gender employment ratio into between-industry dynamics and within-industry dynamics, excluding government employment

(a) Non-fiscal shock
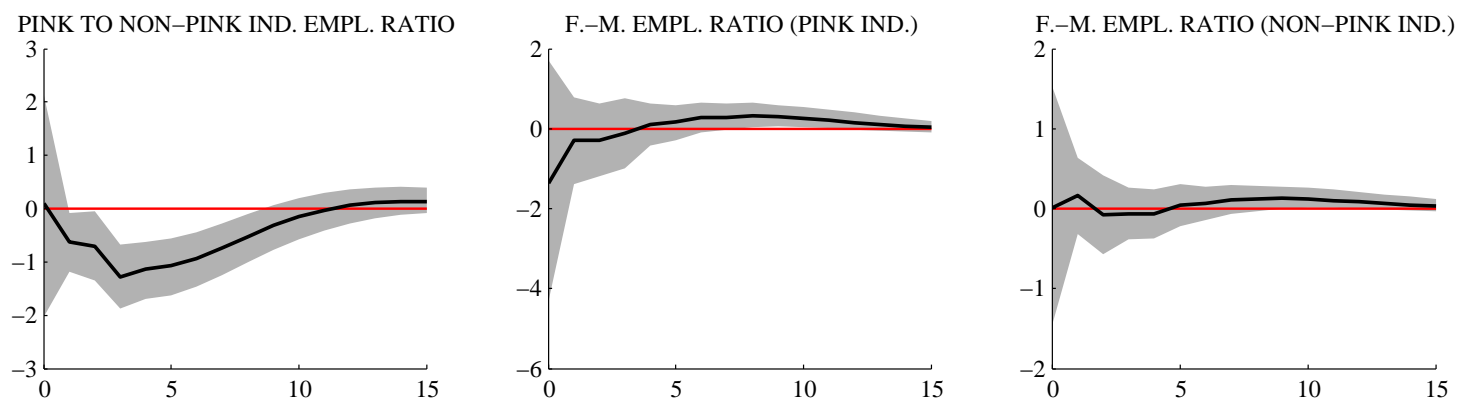

(b) Fiscal shock
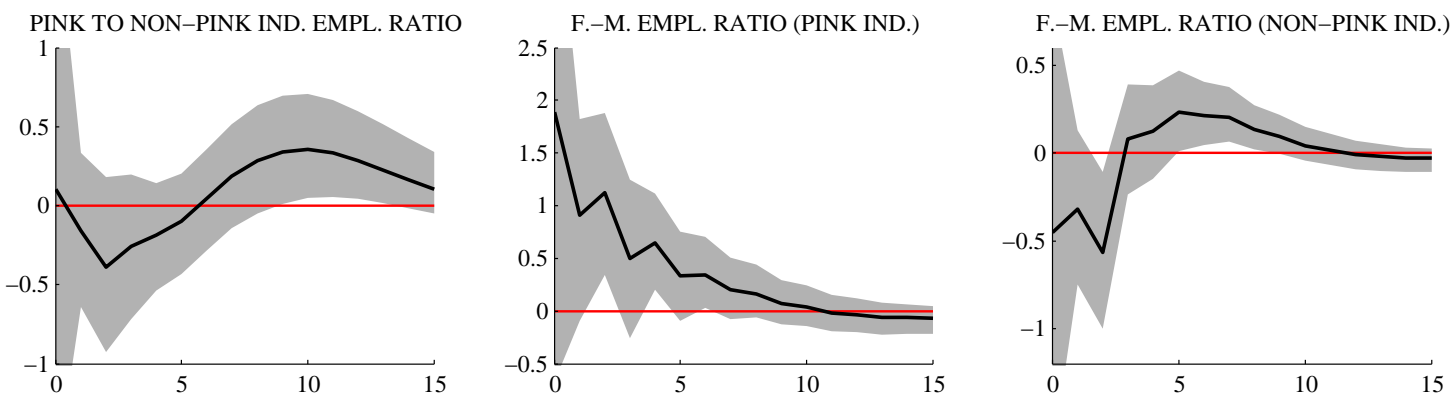

Notes: The solid lines are the median responses and the grey shaded areas show the 16 th- 84 th percentiles of 10,000 estimated responses, sorted at each horizon. The responses are expressed in percentage terms. On the horizontal axes, the horizon is given in quarters. The median impact response of GDP (not shown) is normalized to one percent. 